\title{
Control Strategy to Start a Shaft Generator System Employing DFIM Under Power Take Me Home Mode
}

\author{
Tong Zhao, Dawei Xiang, and Yan Zheng
}

\begin{abstract}
Comparing to the traditional synchronous or induction electric machines, the doubly-fed induction machine (DFIM) with the partially rated converter is a good solution for a shaft generator system which normally operates within a relatively small adjustable speed range. However, the application of DFIM is limited in the real systems due to the lack of self-start capability under the power take me home (PTH) mode when the main engine fails. To overcome this problem, an approach is proposed in this paper. The basic idea is first to start the machine in the induction machine (IM) mode feeding from the ship-borne power grid (SPG) and then to switch over into the DFIM mode when the speed reaches its normal speed range. The hardware scheme, start procedure and control algorithm of the start approach are presented in the paper. Simulation and experimental studies were carried out to validate the feasibility and effectiveness of the approach.
\end{abstract}

Index Terms-doubly-fed induction machine (DFIM), power take me home (PTH), shaft generator system.

\section{INTRODUCTION}

$\mathrm{O}$ WING to the increasing pressure on global environmental and energy resources, there is a technical trend to continuously reduce fossil fuel consumption and the $\mathrm{CO}_{2}$ emission for ships [1]-[3]. Moreover, the global economic crisis makes managers more sensitive about the cost of international sea transportation [4]-[8]. As a result, more and more attention has recently been paid to the shaft generation (SHG) technology.

In an SHG system as shown Fig. 1, a shaft machine is connected with the main engine (mostly a diesel engine) by clutches and gear box, which can operate as a generator or a motor. It helps the conventional ship propulsion system to improve not only the energy efficiency but also the system reliability. When the main engine (ME) fails, the shaft machine can drive the whole ship independently at a lower speed in order to return to a port, which is called as the power take me home (PTH) mode.

According to the rating of the power converter, the SHG systems could be divided into two types, i.e., the fullpower shaft generator (FPSG) system and doubly-fed shaft generator (DFSG) system. The FPSG system has a wide speed range which can be easily started to drive

Manuscript received January 23, 2019. This paper was presented in part at the 2018 IEEE International Power Electronics and Application Conference and Exposition (PEAC), Shenzhen, China, November 2018.

All authors are with the College of Electronics and Information Engineering, Tongji University, Shanghai, China (email: zhaotong11234@163.com).

Digital Object Identifier 10.24295/CPSSTPEA.2019.00012

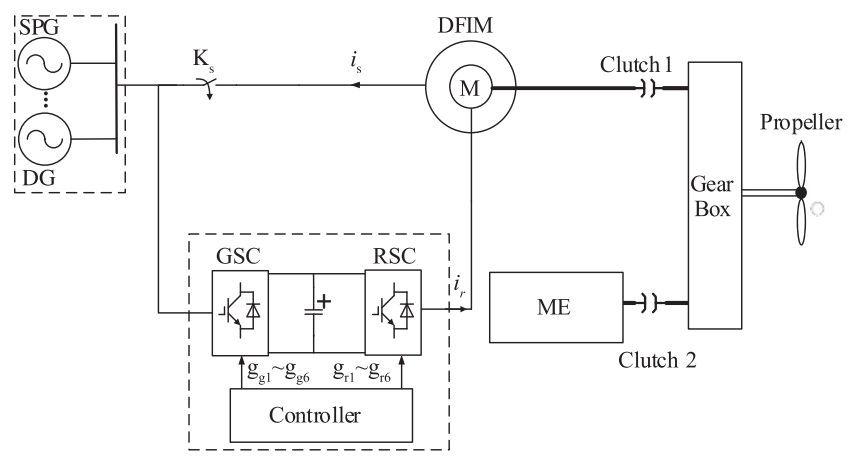

(a)

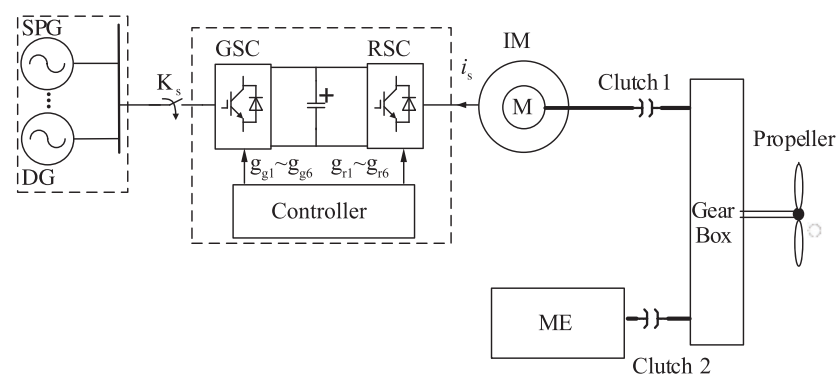

(b)

Fig. 1. Structures of SHG system. (a) Doubly-fed shaft generator system. (b) Full-power shaft generator system.

the ship without ME in PTH mode. However, a larger capacity of the converter is demanded in the FPSG system, which increases the cost and volume of the system in the limited room on board [9]-[10]. DFSG system has less cost and smaller volume because of the smaller capacity of the converter. Unfortunately, its speed range is relatively small, which cannot be directly started from a standstill and operated in PTH mode [11]-[15].

To overcome the self-start difficulty of DFSG system, an approach is proposed in this paper. The basic idea is first to start the machine in the induction machine (IM) mode feeding from the ship-borne power grid (SPG) and then to switch over into the DFIM mode when the speed reaches its normal speed range. Simulation is carried out to verify the feasibility and effectiveness of this approach. To clarify the method, the remaining paper is organized as follows. Firstly, the principle of this approach is described in Section II including the hardware scheme, start process and control algorithm. Then, a typical $500 \mathrm{~kW}$ DFSG system is studied using MATLAB/Simulink in Section III to prove the method. After that, an experimental platform is built and 


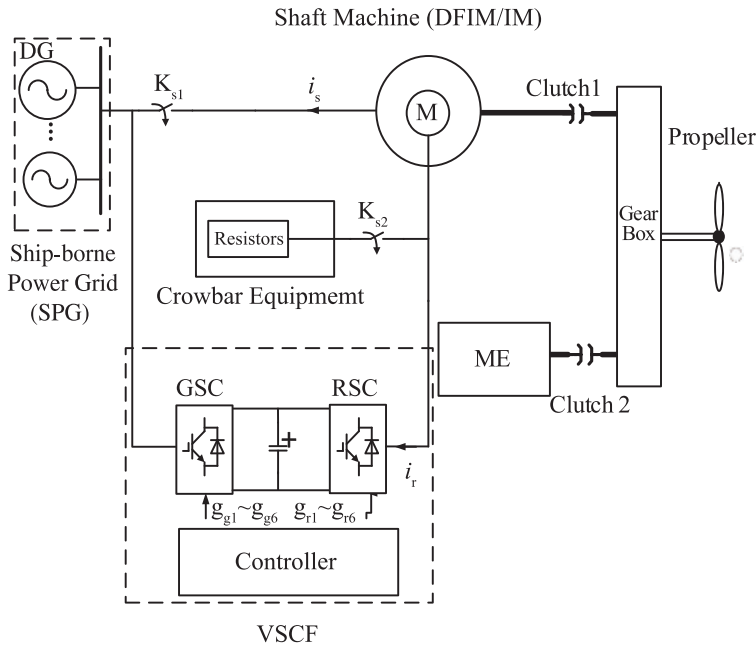

Fig. 2. Structure of the improved DFSG system.

experimental results show the practical application effect of this method in Section IV. Finally, the conclusion is made in Section V to highlight the advantages of the method.

\section{DFIM Shaft Generator System Start Approach UNDER PTH MODE}

\section{A. Principle}

The method proposed in this paper aims at starting the DFIM from a standstill under PTH mode, which can hardly be realized in a conventional DFIM system. The key of this approach is to modify the DFIM into an induction machine to start it from a standstill. Specifically, the machine is firstly converted into an IM by shorting the three-phase rotor windings. Then, the machine can be started as an IM until its speed reaches the DFIM speed range. After that, the threephase rotor windings will be opened to allow the machine operating in the DFIM mode to drive the ship independently under PTH mode.

This method switches the machine operating between the IM and DFIM modes. By combining the advantages of IM (self-start) and DFIM (partial-rated converter) together, it can effectively improve the technical and economic performance of SHG technology.

\section{B. Hardware Scheme}

Comparing with the conventional solution, a crowbar with $\mathrm{K}_{\mathrm{s} 2}$ and resistors (for rotor current limitation) are added in the improved DFSG system (see in Fig. 2), which enables the machine to switch between DFIM and IM modes. When $\mathrm{K}_{\mathrm{s} 2}$ is closed, the rotor windings are short-circuited and the machine works like an IM. $\mathrm{K}_{\mathrm{s} 2}$ cannot be opened until the speed exceeds the minimum speed of DFIM mode.

As shown in Fig. 2, the ship-borne power grid (SPG) is powered by several diesel generators (DG). The improved DFSG system has two switches, $\mathrm{K}_{\mathrm{s} 1}$ and $\mathrm{K}_{\mathrm{s} 2}$. $\mathrm{K}_{\mathrm{s} 1}$ connects the

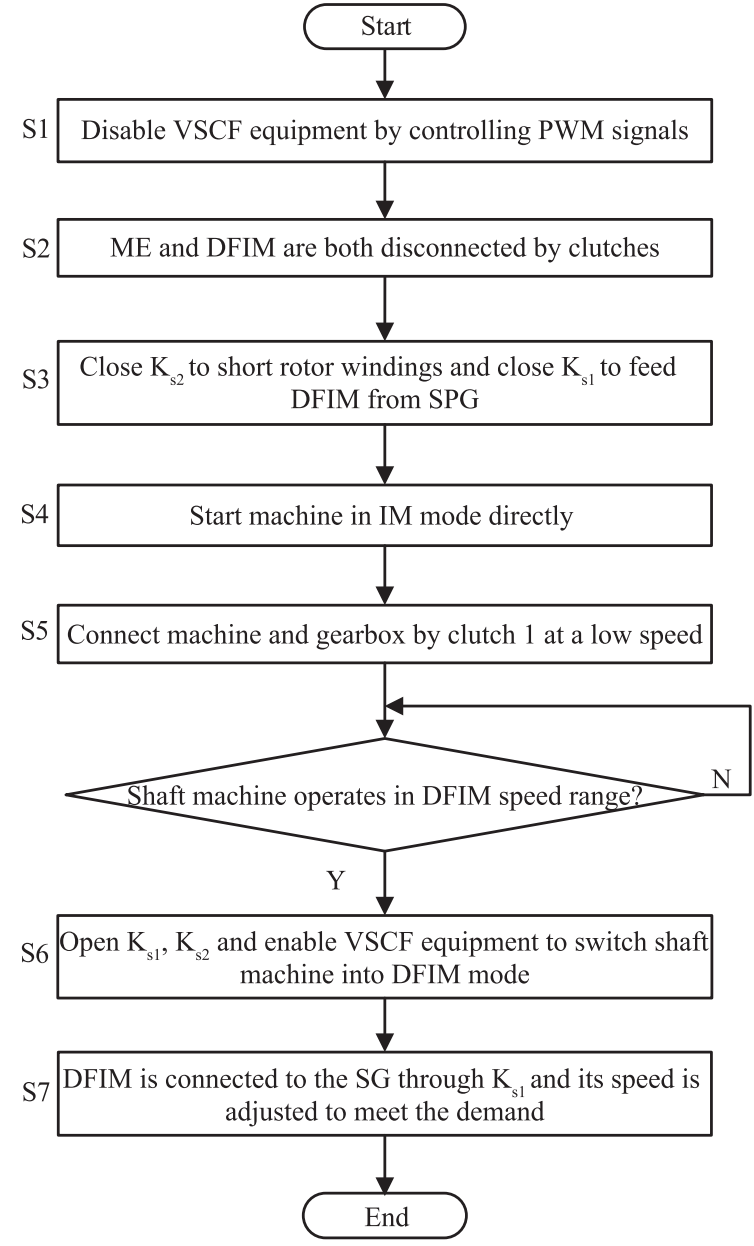

Fig. 3. Flow chart of start process of DFSG system under PTH mode.

stator to the SPG directly. $\mathrm{K}_{\mathrm{s} 2}$ connects with the three-phase rotor windings. Meanwhile, the rotor is also connected with a variable-speed constant-frequency (VSCF) equipment, which consists of a back-to-back grid side converter (GSC) and rotor side converter (RSC). There is a controller inside the VSCF equipment that controls RSC and GSC by PWM signals.

Two clutches are connected between the gearbox and the shaft machine and ME respectively, by which the propulsion power can be independently transmitted to the propeller to drive the ship.

\section{Start Procedure}

\section{1) Process}

The flow chart of the start process is shown in Fig. 3. Firstly, the VSCF equipment is disabled by blocking the PWM signals. Secondly, both the ME and DFIM are disconnected by clutches. Then, $\mathrm{K}_{\mathrm{s} 2}$ will be closed and the machine works in IM mode. After that, the machine is started by closing $\mathrm{K}_{\mathrm{sl}}$ feeding from the SPG. Then the machine will be connected to the gear box and propeller by closing the clutch 1 at a low speed (e.g., 150 rpm). 
After the speed increases gradually and exceeds the minimum speed of DFIM, the machine is ready to switch over into the DFIM mode. Then, $\mathrm{K}_{\mathrm{s} 1}$ and $\mathrm{K}_{\mathrm{s} 2}$ will be opened to disconnect the SPG and shorting the rotor windings. Due to the large inertia, the machine speed will be maintained for a while, during which the stator voltage can be established and stabilized. Finally, $\mathrm{K}_{\mathrm{s} 1}$ is closed and the machine controlled by the VSCF equipment is connected to the SPG. At this time, the start process is finished and the ship can be driven by the DFIM under PTH mode. Note that, the step S6 could be simplified by only open $\mathrm{K}_{\mathrm{s} 2}$ with $\mathrm{K}_{\mathrm{s} 1}$ remaining closed, but $\mathrm{K}_{\mathrm{s} 2}$ must be switched at current zero crossing point to avoid switching over-voltage.

\section{2) Mode Switching}

As the key step in the whole start process, the mode switching process between IM and DFIM modes (S6 in Fig. 3) can be divided into 2 sub-steps as follows:

\section{Sub-Step 1: Field Energy Dissipation}

$\mathrm{K}_{\mathrm{s} 1}$ is opened and $\mathrm{K}_{\mathrm{s} 2}$ is kept closed until the stator voltage reduces to an acceptable level. During this sub-step, the electromagnetic field energy in the shaft machine is mainly dissipated by the crowbar resistor.

\section{Sub-Step 2: Re-Excitation}

After field energy dissipation, open $\mathrm{K}_{\mathrm{s} 2}$ and re-excite the machine by the VSCF equipment to establish a stable stator voltage identical to voltage of SPG ready for grid integration.

\section{Control Algorithms}

During the start process, the machine operates in two modes depending on whether the rotor windings are close or open. While the speed is less than the minimum DFIM speed, the rotor windings are shorted by $\mathrm{K}_{\mathrm{s} 2}$. The machine is fed from the SPG by closing $\mathrm{K}_{\mathrm{s} 1}$ and started directly in IM mode. As the machine's speed increases, $\mathrm{K}_{\mathrm{s} 1}$ and $\mathrm{K}_{\mathrm{s} 2}$ will not be opened until the machine enters into the DFIM normal speed range. And then, the machine is converted to DFIM mode by switching $\mathrm{K}_{\mathrm{s} 1}$ and $\mathrm{K}_{\mathrm{s} 2}$ properly.

In IM mode, the shaft machine is directly started by the SPG. Some electromechanical impact (over-current and electromagnetic torque oscillation) will occur, due to the low power factor at low speed and the effect of transient DC stator flux. However, since the transient is short (typically several seconds), it is considered that the impact is tolerable for the system.

In DFIM mode, the machine is controlled by the VSCF equipment using the grid voltage oriented control algorithm (GVOC) [16]-[17]. The structure of GVOC is shown in Fig. 4. The active and reactive powers are decoupled through Park transformation and controlled by $i_{\mathrm{rd} \text { ref }}$ and $i_{\mathrm{rq} \text { ref }}$ respectively.

$\theta_{\mathrm{g}}$ is the angle of Park transformation obtained from the phase locked loop (PLL) as shown in Fig. 5. $U_{\mathrm{sq}}$ and $U_{\mathrm{sq}}^{*}$ are

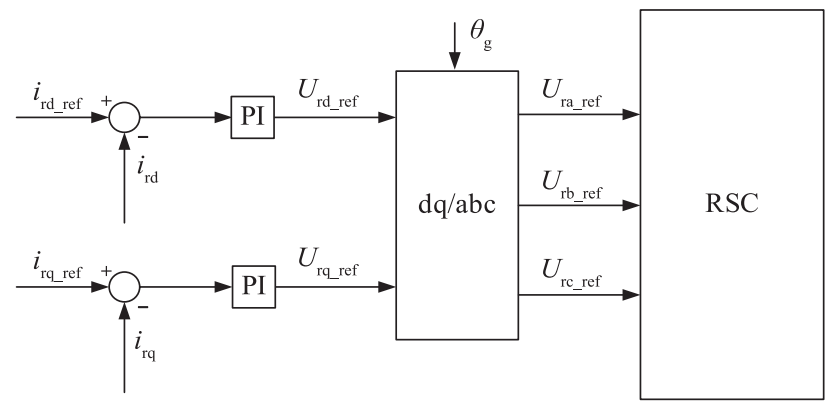

Fig. 4. Block diagram of GVOC control algorithm for DFIM.

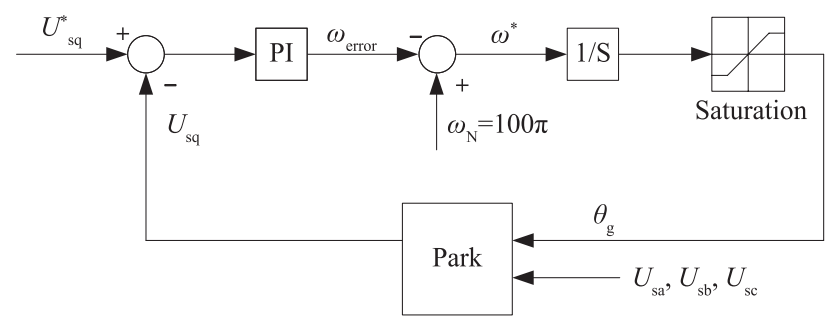

Fig. 5. Block diagram of PLL.

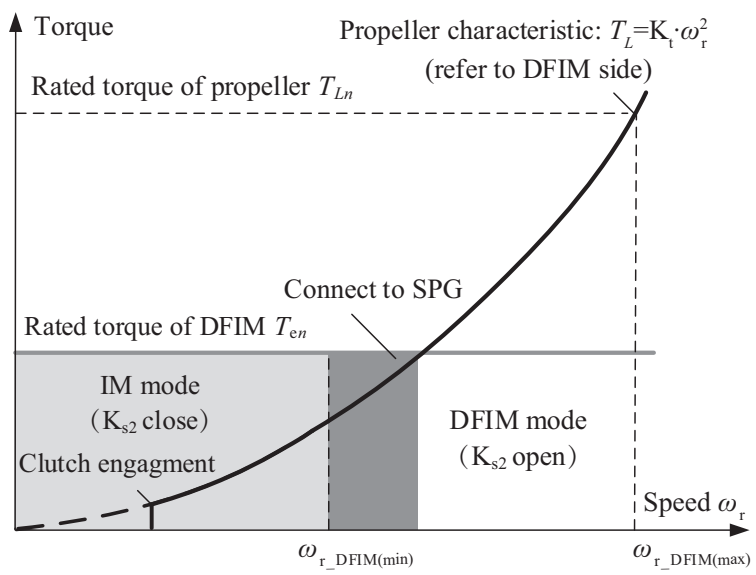

Fig. 6. The torque-speed characteristics of DFSG system with PTH capability.

used to calculate $\omega_{\text {error }}$, which is added to $\omega_{\mathrm{N}}$ to estimate $\omega^{*}$. Then, $\omega^{*}$ is integrated to obtain $\theta_{\mathrm{g}}$. The detailed description of PLL can be found in [18].

The control algorithm proposed above allows the machine to start from the standstill and propel the ship under PTH mode. By overcoming the difficulty of DFIM self-start, the method will facilitate the application of DFIM in the SHG systems.

\section{E. Capacity Matching Relationship in DFSG System}

As shown in Fig. 2, a DFSG system is mainly composed of DFIM, VSFC, SPG, propeller and ME. To ensure a reliable PTH start, their capacities must be well matched. Theoretically, the capacity matching relationship is decided by the torque-speed characteristics of DFSG system as show in Fig. 6, where the critical constrain is that the rated torque 
of DFIM $T_{e(n)}$ must be greater than the propeller torque (refer to DFIM side) at the minimum speed of DFIM mode $\omega_{r-\operatorname{DFIM}(\min )}$ to ensure the system can be started in PTH mode. Consequently, the capacity matching relationship between different units could be derived in the equations as below.

$$
\begin{gathered}
T_{\mathrm{e}(n)}>T_{L} @ \omega_{\mathrm{r} \_\mathrm{DFIM}(\min )} \Rightarrow P_{\mathrm{DFIM}}>\frac{\left(1-s_{\max }\right)^{2}}{\left(1+s_{\max }\right)^{3}}=P_{\mathrm{PP}} \\
P_{\mathrm{VSFC}}=S_{\max } P_{\mathrm{DFIM}} \\
P_{\mathrm{DE}}=\left(1+s_{\text {max }}\right) P_{\mathrm{DFIM}}+P_{\mathrm{PP}} \\
P_{\mathrm{SPG}}>P_{\mathrm{DFIM}}
\end{gathered}
$$

Where, $T_{\mathrm{e}(n)}$ and $T_{L}$ are the torques of DFIM and propeller (refer to DFIM side) respectively; $\omega_{r_{-} D F I M(\min )}, \omega_{r_{-} D F I M(\max )}, s_{\max }$ are the minimum speed, maximum speed and maximum slip ratio of DFIM; $P_{\mathrm{DFIM}}, P_{\mathrm{VSFC}}, P_{\mathrm{PP}}, P_{\mathrm{DE}}, P_{\mathrm{SPG}}$ are the nominal power ratings of DFIM, VSFC, propeller, the main engine and ship-borne power grid. It is noted that the equations above are the theoretical critical limitations. In a real system, some design margins must be given for system safety and reliability.

It can be seen in (1) and (2) that a larger speed operation range is preferred for a less power rating of DFIM with PTH capability but at the cost of higher power rating of VSFC. The tread-off between the capacities of DFIM and VSFC must be carefully considered at the stage of design, which affects the overall economic and technical performance of the system.

\section{SimUlation StUdY}

\section{A. Simulation Model}

In order to verify the feasibility and effectiveness of the proposed method, a $500 \mathrm{~kW}$ DFSG system was designed and simulated using MATLAB/Simulink as shown in Fig. 7. The parameters of the simulation system and DFIM are listed in Table I and Table II respectively. Note that, the rated values are used as the basic values of per unit (p.u.) in this paper.

The torque-speed characteristics of the shaft machine and propeller are plotted in Fig. 8. It is shown that the propeller can be driven by the shaft machine operating in IM mode at low speed. When rotor speed $\omega_{\mathrm{r}}$ reaches the minimum speed of DFIM (700 rpm), the operation mode will be changed from IM to DFIM by switching $\mathrm{K}_{\mathrm{s} 1}$ and $\mathrm{K}_{\mathrm{s} 2}$. Then, the machine is connected into the SPG so that the ship can be driven in DFIM mode while its speed is between $700 \mathrm{rpm}$ and $800 \mathrm{rpm}$. During the start process, the propeller prefers to connect into the shaft machine by clutch 1 at a relatively low speed for safety reason.

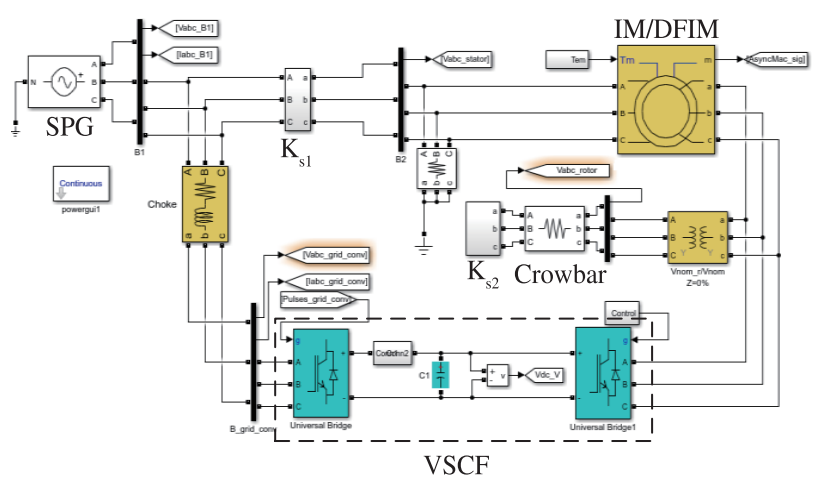

Fig. 7. Simulation model of the improved DFSG system.

TABLE I

Parameters of Simulation DFSG System

\begin{tabular}{lc}
\hline \hline Rated ME power & $2.15 \mathrm{MW}$ \\
Rated propeller power & $1.5 \mathrm{MW}$ \\
Rated propeller speed & $216.7 \mathrm{rpm}$ \\
Rated DC bus voltage & $700 \mathrm{~V}$ \\
Rated RSC capacity & $160 \mathrm{kVA}$ \\
Switching frequency & $3 \mathrm{kHz}$ \\
Gearbox speed ratio & $1: 6$ \\
Clutch engagement speed & $150 \mathrm{rpm}$ \\
Crowbar resistor & $0.2 \Omega$ \\
Inertia time constant of drive train & $5.5 \mathrm{~s}$ \\
\hline \hline
\end{tabular}

TABLE II

Parameters of DFIM

\begin{tabular}{lc}
\hline \hline Rated power & $500 \mathrm{~kW}$ \\
Rated stator line-to-line voltage & $400 \mathrm{~V}$ \\
Rated frequency of stator & $50 \mathrm{~Hz}$ \\
Open circuit voltage of rotor & $1150 \mathrm{~V}$ \\
Pole pairs & 3 \\
Rated speed & $1300 \mathrm{rpm}$ \\
Normal speed range & $700 \sim 1300 \mathrm{rpm}$ \\
\hline \hline
\end{tabular}

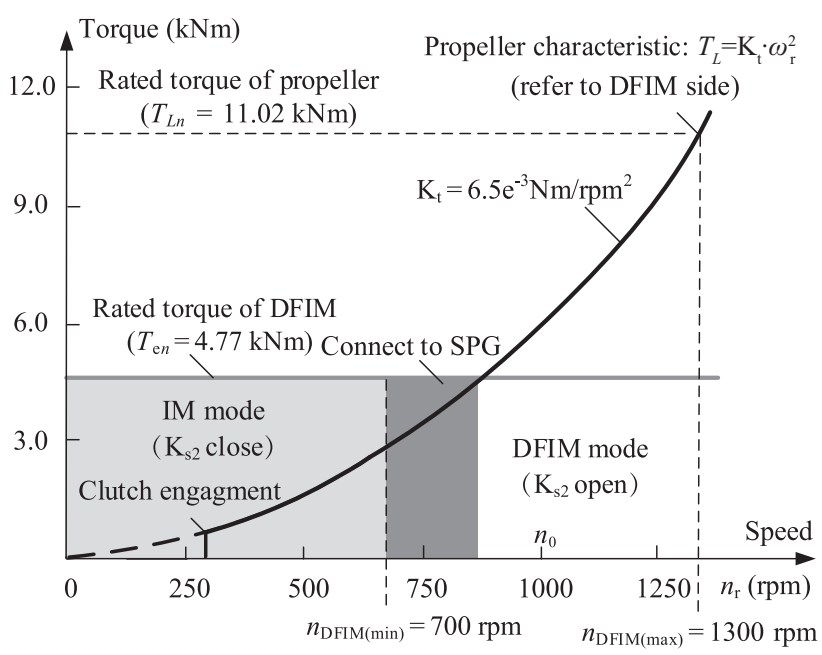

Fig. 8. The torque-speed characteristics of the improved DFSG system. 


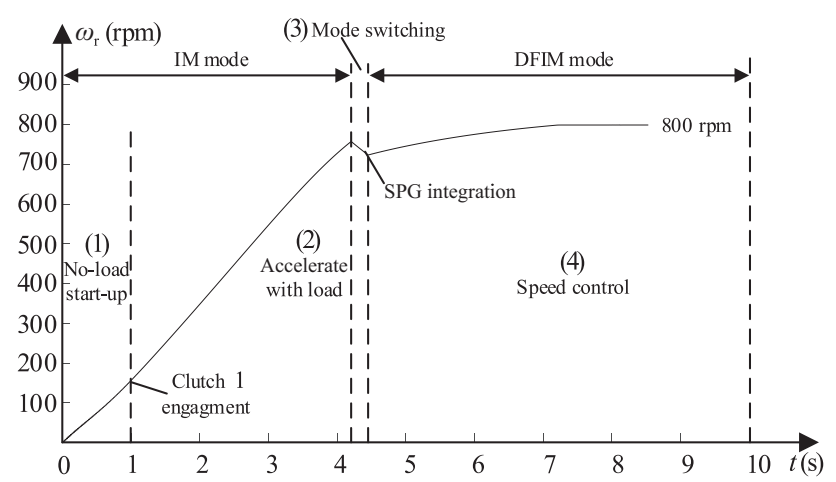

Fig. 9. Speed of shaft machine during start process under PTH mode.

\section{B. Simulation Results}

\section{1) Results of the Start Process}

Simulation has been carried out to study the performance of the proposed DFSG start approach under PTH mode. The simulation results are as summarized in Figs. 9-16.

The speed of shaft machine during the start process is plotted in Fig. 9. Firstly, the shaft machine starts under noload condition by closing $\mathrm{K}_{\mathrm{s} 1}$ and $\mathrm{K}_{\mathrm{s} 2}$ in IM mode. Secondly, the propeller is connected into the machine by clutch 1 at a low speed $(150 \mathrm{rpm})$. While its speed enters the normal DFIM speed region ( $>700 \mathrm{rpm})$, the machine is then switched into DFIM mode by opening $\mathrm{K}_{\mathrm{s} 1}, \mathrm{~K}_{\mathrm{s} 2}$ and enabling VSCF equipment. During the mode switching process, a small speed decrease can be observed in Fig. 9 since the shaft machine is out of power and the speed is maintained by the inertia effect of the drive train. It, therefore, requires that the mode switching process could be completed as soon as possible.

After the SPG integration, the ship can finally be driven by the shaft machine under PTH mode independently. It takes about $10 \mathrm{~s}$ to complete the whole start process, which is fast enough for ship and mainly decided by the capacity of shaft machine and the aggregated inertia of drive train (including shaft machine, gear box and propeller). Note that, the adjustable maximum speed (about $800 \mathrm{rpm}$ ) is limited by the rated torque of shaft machine as shown in Fig. 8, which is much less than its nominal maximum speed under the hybrid generation and propulsion modes with ME (1300 rpm).

As shown in Fig. 10, the electromagnetic torque $T_{\mathrm{em}}$ oscillates at the beginning of the start-up, which is a typical characteristic of induction machine being started directly in full voltage. The oscillation only lasts for a short time (within $2 \mathrm{~s})$ so that it will not damage the machine.

The waveform of stator voltage $U_{\text {stator }}$ is plotted in Fig. 11 . It is shown that the stator voltage is restrained by the SPG when the stator connects with SPG in both IM and DFIM modes. In the mode switching process, the stator voltage drops as the result of field energy dissipation.

The waveform of stator current $I_{\text {stator }}$ and rotor current $I_{\text {rotor }}$ are plotted in Figs. 12 and 13. While the machine works

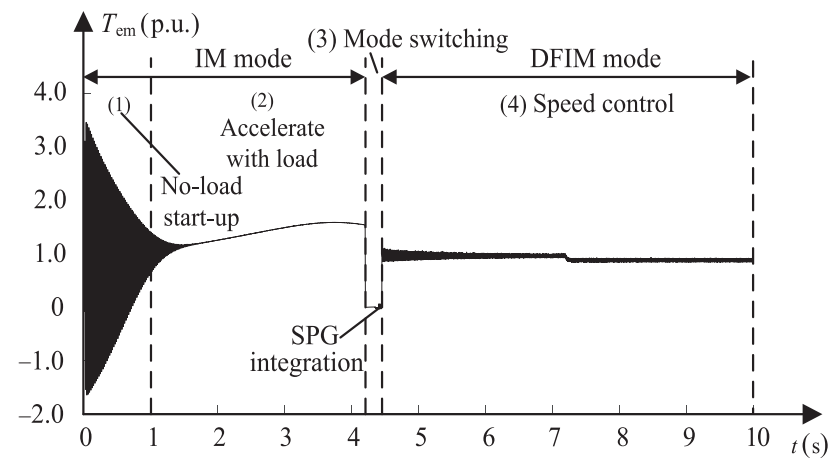

Fig. 10. Electromagnetic torque of shaft machine during start process under PTH mode.

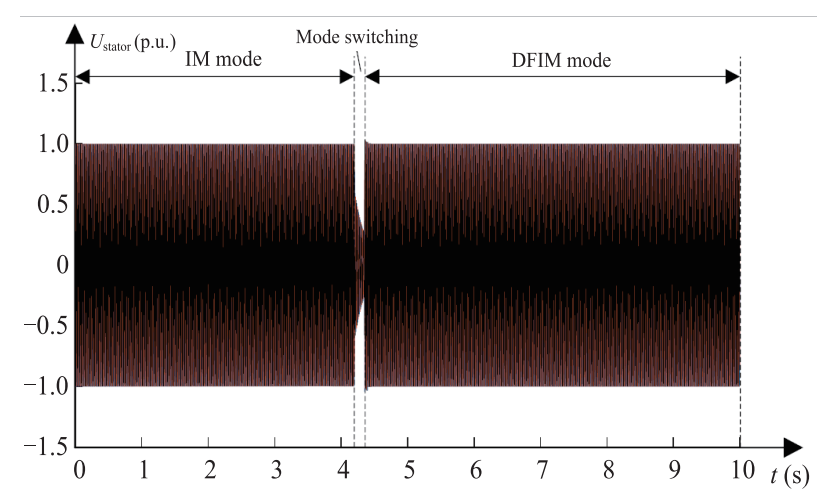

Fig. 11. Stator voltage of shaft machine during start process under PTH mode.

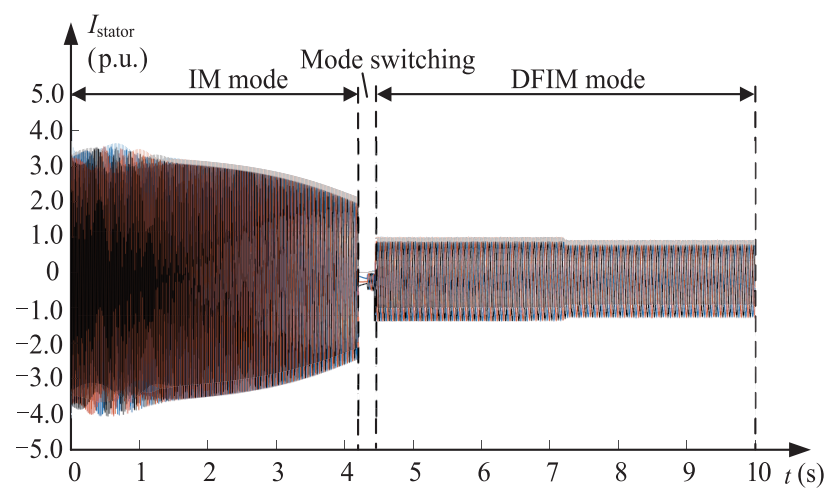

Fig. 12. Stator current of shaft machine during start process under PTH mode.

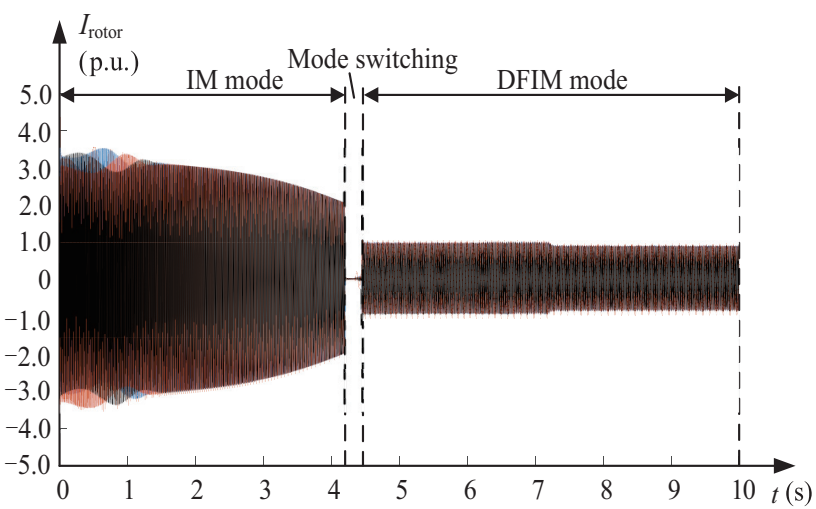

Fig. 13. Rotor current of shaft machine during start process under PTH mode. 


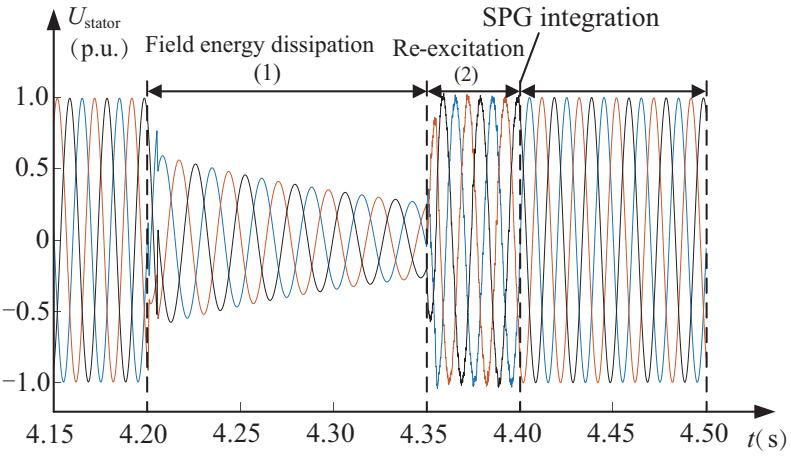

Fig. 14. The detailed waveform of stator voltage during mode switching.

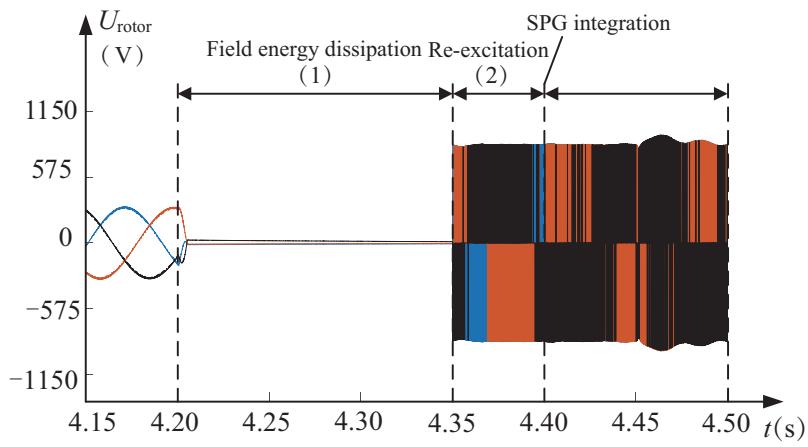

Fig. 15. The detailed waveform of rotor voltage during mode switching.

in IM mode, about 3 times over-current can be seen in the simulation results immediately after the machine is started up. The currents decrease gradually following the speed increase within $4 \mathrm{~s}$. Note that, the large starting current will cause a non-negligible impact on both SPG and the electric machine. This could be suppressed by using the SCR based soft-start technique but with some additional equipment and cost. After switch into the DFIM mode, the currents are controlled in the nominal value to propel the ship under PTH mode safely.

\section{2) Results of the Mode Switching Process}

To further clarify the method, the detailed simulation results during mode switching process are plotted in Figs. 14 -17 .

After $\mathrm{K}_{\mathrm{s} 1}$ is opened, the VSCF equipment cannot be directly enabled to control the shaft machine. Before reexcitation by the VSCF equipment, the electromagnetic field energy in the machine must be well dissipated. To speed the process, $\mathrm{K}_{\mathrm{s} 2}$ is kept closed and the energy is mainly consumed by the crowbar resistor in the sub-step (1). As a result, $U_{\text {stator }} U_{\text {rotor }}$ and $I_{\text {rotor }}$ reduce gradually (shown in Figs. 14-17). Meanwhile, Istator reduces to zero quickly (shown in Fig. 16). $\mathrm{K}_{\mathrm{s} 2}$ will not be opened until $U_{\text {stator }} U_{\text {rotor }}$ and $I_{\text {rotor }}$ reduce to an acceptable level which is ready for enabling the VSCF equipment.

In the sub-step of re-excitation, the machine is controlled by the VSCF equipment. It is shown that the rotor current

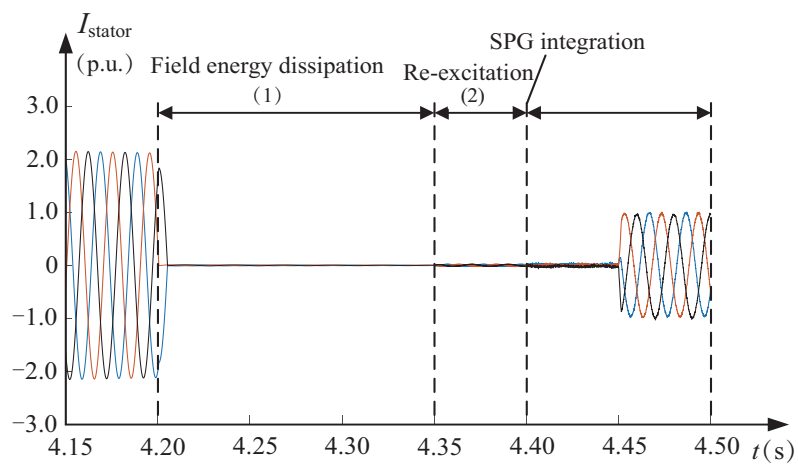

Fig. 16. The detailed waveform of stator current during mode switching.

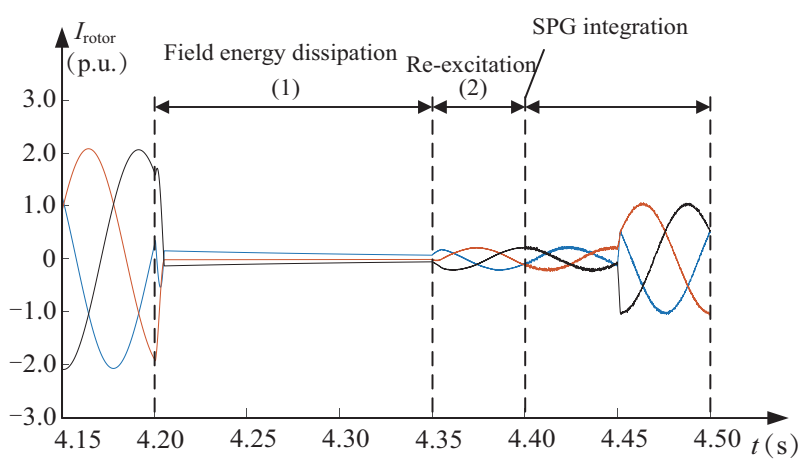

Fig. 17. The detailed waveform of rotor current during mode switching.

$I_{\text {rotor }}$ increases within $50 \mathrm{~ms}$ to the magnetization current level (see Fig. 17) and the stator voltage Ustator is established (see Fig. 15) ready for grid integration. As shown in Fig. 16, the impact of SPG integration is ignorable.

\section{EXPERIMENTAL STUDY}

Experimental study was carried out to validate the feasibility and effectiveness of the method.

\section{A. Setup of Experimental Platform}

The experimental platform is shown in Fig. 18 and the parameters are listed in Table III. In this experimental platform, a wound-rotor induction machine is installed to operate as a DFIM. The VSCF equipment contains two PWM converters, where GSC adopts a commercial $15 \mathrm{~kW}$ active front end (AFE) and RSC is built using a $1200 \mathrm{~V} / 100 \mathrm{~A}$ IGBT power module. The controller is designed based on the TMS320F28335 DSP. For safety reason, the DFIM operates under the derating conditions (less than $300 \mathrm{~V} / 3.5 \mathrm{kVA}$ ) through a variac. Switching of the machine between DFIM and IM modes is realized by $\mathrm{K}_{\mathrm{s} 2}$.

\section{B. Experimental Results}

The proposed method is tested on the experimental platform. The waveforms of stator voltage $U_{\text {sab }}$, grid voltage 


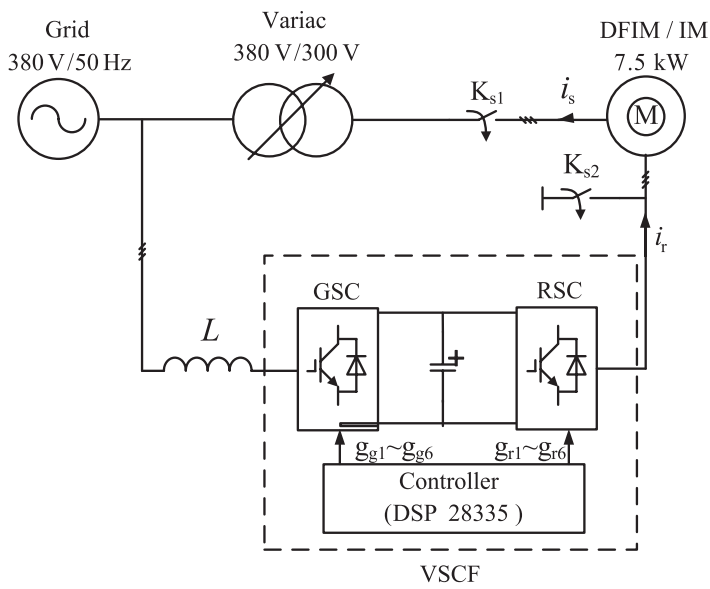

(a)
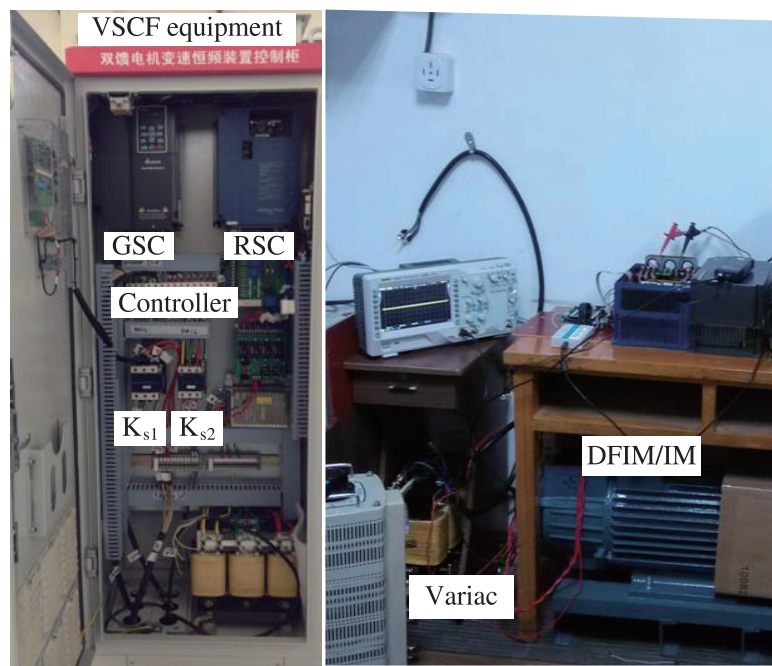

(b)

Fig. 18. Setup of experimental platform. (a) Schematic diagram. (b) Picture of experimental platform.

TABLE III

Parameters of Experimental Platform

\begin{tabular}{ccc}
\hline \hline & Rated power & $7.5 \mathrm{~kW}$ \\
& Rated speed & $1300 \mathrm{rpm}$ \\
& Rated rotor current & $26.5 \mathrm{~A}$ \\
DFIM/IM & Rated stator current & $18 \mathrm{~A}$ \\
& Stator/rotor ratio & 2.05 \\
& Pole pairs & 3 \\
& Range of slip & $-0.3 \sim 0.3$ \\
\hline \multirow{3}{*}{ RSC } & IGBT module & 7 MBR100U4B120 \\
& Rated de voltage & $580 \mathrm{~V}$ \\
& Rated current & $50 \mathrm{~A}$ \\
\hline \multirow{4}{*}{ GSC } & Model & Delta:AFE150A43 \\
& Rated power & $15 \mathrm{~kW}$ \\
& Rated input & $323 \sim 528 \mathrm{~V} \mathrm{35} \mathrm{A}$ \\
& Rated output & DC 660 V 33 A \\
& L filter & $4.18 \mathrm{mH} / 35 \mathrm{~A}$ \\
\hline \hline
\end{tabular}

$U_{\text {gab }}$, stator current $i_{\mathrm{sa}}$ and rotor current $i_{\mathrm{ra}}$ during the start process under PTH mode are plotted in Figs. 19-22.

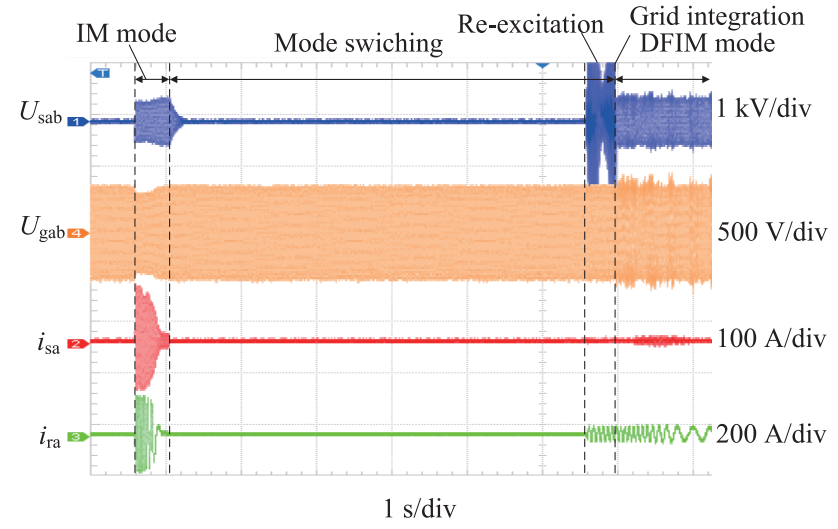

Fig. 19. The waveforms of start process under PTH operation.

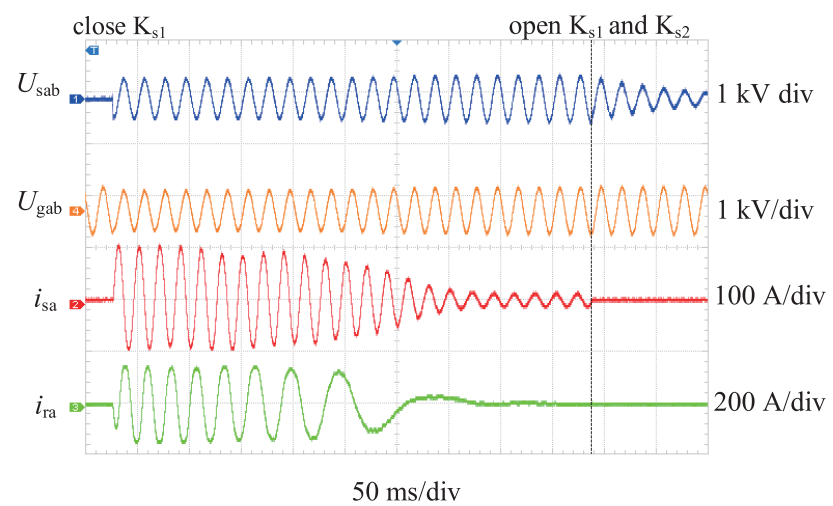

Fig. 20. The detailed waveforms during machine start in IM mode.

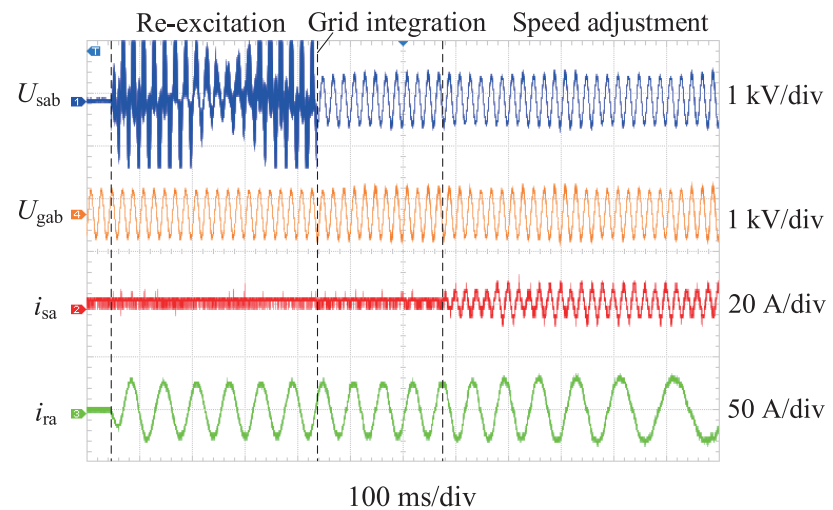

Fig. 21. The detailed waveforms during mode switching process.

The waveforms of the whole start process under PTH operation are shown in Fig. 19. Firstly, the machine with rotor windings shorted by $\mathrm{K}_{\mathrm{s} 2}$ is connected to the grid directly through $\mathrm{K}_{\mathrm{s} 1}$. Then, $\mathrm{K}_{\mathrm{s} 1}$ and $\mathrm{K}_{\mathrm{s} 2}$ are opened when the speed exceeds the normal range of DFIM. After that, the machine is re-excited and integrated into the grid so that it can operate as a normal DFIM. So far, the whole start process is completed.

The detailed waveforms during machine start in IM mode are shown in Fig. 20. It can be seen that the stator voltage $U_{\text {sab }}$ increases to the grid voltage $U_{\text {gab }}$ immediately after $\mathrm{K}_{\mathrm{s} 1}$ is closed and decreases rapidly after $\mathrm{K}_{\mathrm{s} 1}$ and $\mathrm{K}_{\mathrm{s} 2}$ are opened. 


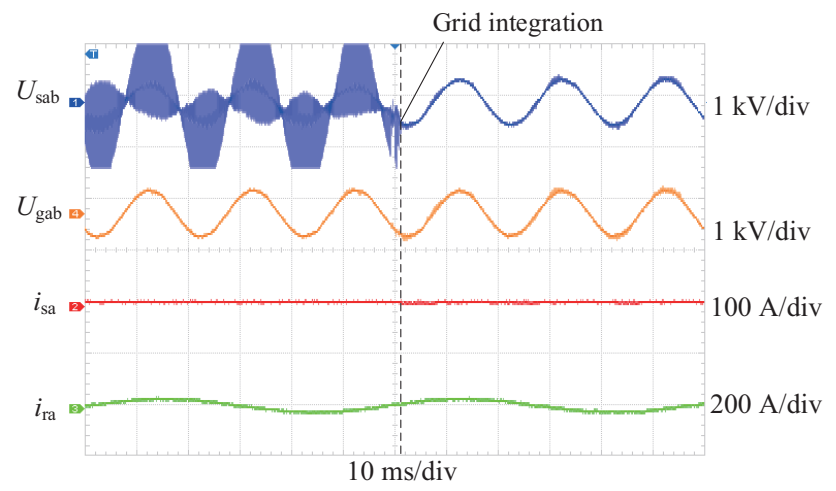

Fig. 22. The detailed waveforms during grid integration.

The stator and rotor currents $\left(i_{\mathrm{sa}}\right.$ and $\left.i_{\mathrm{ra}}\right)$ reach about 4 times over-current shortly (less than $350 \mathrm{~ms}$ ) after $\mathrm{K}_{\mathrm{s} 1}$ is closed, which is consistent with the simulation results. When the speed increases, the frequency of rotor current $i_{\text {ra }}$ reduces to $0 \mathrm{~Hz}$ gradually and the stator current $i_{\mathrm{sa}}$ also reduces to a relatively small magnetizing current. The speed reaches $1000 \mathrm{rpm}$ at the end of the IM mode.

Fig. 21 shows the detailed waveforms during mode switching process to DFIM mode. A stable stator voltage $\mathrm{U}_{\text {sab }}$ is established with the machine re-excitation control, which is critical for grid integration. From Fig. 22, it can be seen that the impact of grid integration is ignorable as a result of precise control. In additionally, the frequency rotor current at the moment grid connection is $15 \mathrm{~Hz}$, which means the speed of DFIM is $700 \mathrm{rpm}$ just within the normal speed range. After grid integration, the stator current $i_{\mathrm{sa}}$ maintains zero until the speed is adjusted.

\section{CONCLuSION}

In this paper, an approach to start an SHG system employing DFIM under PTH mode is presented to reduce the cost and volume of the traditional synchronous or induction machines based SHG systems. The principle of the method is discussed in detail and its feasibility and effectiveness are confirmed by simulation and experimental studies. Research results show that the DFIM SHG system can be easily started under PTH mode with a minor hardware modification and adequate control algorithm. It is expected that this study is helpful to improve the technical and economic performance of SHG technology.

\section{REFERENCES}

[1] T. Zhao, D. Xiang, and Y. Zheng, "An approach to start a shaft generator system employing DFIM under Power take me home mode," 2018 IEEE International Power Electronics and Application Conference and Exposition (PEAC), Shenzhen, China, 2018, pp. 1-5.

[2] B. Bilgin et al., "Making the case for electrified transportation," in IEEE Transactions on Transportation Electrification, vol. 1, no. 1, pp. 4-17, June 2015.

[3] J. Prousalidis, C. Patsios, F. Kanellos, A. Sarigiannidis, N. Tsekouras, and G. Antonopoulos, "Exploiting shaft generators to improve ship efficiency," 2012 Electrical Systems for Aircraft, Railway and Ship Propulsion, Bologna, 2012, pp. 1-6.
[4] J. F. Hansen and F. Wendt, "History and state of the art in commercial electric ship propulsion, integrated power systems, and future trends," in Proceedings of the IEEE, vol. 103, no. 12, pp. 2229-2242, Dec. 2015.

[5] A. Sarigiannidis, A. Kladas, E. Chatzinikolaou, and C. Patsios, "High efficiency shaft generator drive system design for Ro-Ro trailerpassenger ship application," 2015 International Conference on Electrical Systems for Aircraft, Railway, Ship Propulsion and Road Vehicles (ESARS), Aachen, 2015, pp. 1-6.

[6] J. M. Prousalidis, E. Xanthopoulos, and K. Voutzoulidis, "Reactive power sharing in ship energy systems with shaft generators,"Journal of Marine Engineering \& Technology, vol. 8, no. 1, pp. 21-38, Jan. 2009.

[7] P. Michalopoulos, F. D. Kanellos, G. J. Tsekouras, and J. M. Prousalidis, "A method for optimal operation of complex ship power systems employing shaft electric machines," IEEE Transactions on Transportation Electrification, vol. 2, no. 4, pp. 547-557, Dec. 2016.

[8] G. Castles, G. Reed, A. Bendre, and R. Pitsch, "Economic benefits of hybrid drive propulsion for naval ships," 2009 IEEE Electric Ship Technologies Symposium, Baltimore, MD, 2009, pp. 515-520.

[9] A. G. Sarigiannidis, E. Chatzinikolaou, C. Patsios, and A. G. Kladas, "Shaft generator system design and ship operation improvement involving SFOC minimization, electric grid conditioning, and auxiliary propulsion," IEEE Transactions on Transportation Electrification, vol. 2, no. 4, pp. 558-569, Dec. 2016.

[10] G. Sulligoi, S. Castellan, M. Aizza, D. Bosich, L. Piva, and G. Lipardi, "Active front-end for shaft power generation and voltage control in FREMM frigates integrated power system: Modeling and validation," International Symposium on Power Electronics Power Electronics, Electrical Drives, Automation and Motion, Sorrento, 2012, pp. 452457.

[11] L. Diao, D. Wang, Z. Peng, L. Guo, and H. Wang, "Sensorless control of a stand-alone doubly-fed induction machine for ship shaft generator systems," Fifth International Conference on Intelligent Control and Information Processing, Dalian, 2014, pp. 373-377.

[12] F. Xiong and X. Wang, "Design and performance analysis of a brushless doubly-fed machine for stand-alone ship shaft generatorsystems," 2011 International Conference on Electrical and Control Engineering, Yichang, 2011, pp. 2114-2117.

[13] J. Lan, Y. Shi, Y. Wu, et al. "A new vector control scheme for the brushless doubly fed induction machine in shaft generation," 2015 IEEE Conference on Energy Conversion (CENCON), Johor Bahru, 2015, pp. 149-154.

[14] S. Kubal, Vacon NXP Grid Converter in Marine Application, Vacon, UK.

[15] J. C. Dermentzoglou, "Investigating the incorporation of a doublyfed induction machine as a shaft generator into a ship's system: Application of a vector control scheme for controlling the doubly fed induction machine," 2014 International Conference on Electrical Machines (ICEM), Berlin, 2014, pp. 2319-2324.

[16] B. K. Bose, Modern Power Electronics and AC Drives, Prentice Hall PTR, 2001.

[17] E. E. Özsoy, E. Golubovic, A. Sabanovic, and M. Gökasan, "A stator voltage oriented doubly fed induction generator control method with a disturbance observer," Eurocon 2013, Zagreb, 2013, pp. 1102-1107.

[18] V. Kaura and V. Blasko, "Operation of a phase locked loop system under distorted utility conditions," Applied Power Electronics Conference and Exposition, 1996. APEC '96. Conference Proceedings 1996, Eleventh Annual, San Jose, CA, 1996, pp. 703-708, vol. 2.

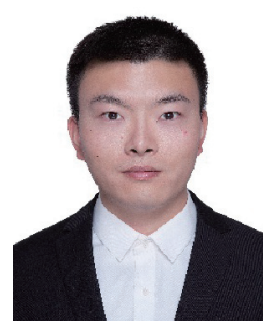

Tong Zhao received the B.S. degree in automation from the University of Shanghai for Science and Technology, Shanghai, China, in 2016, and the M.S. degree in 2019 from the College of Electronics and Information Engineering, Tongji University, Shanghai, China.

His research interests include electric machine control and IGBT module condition monitoring and fault prognosis in NPC three-level converter. 


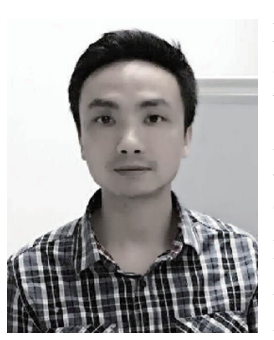

Dawei Xiang received the B.S., M.S., and Ph.D. degrees in electrical engineering from Chongqing University, Chongqing, China, in 1999, 2002, and 2006, respectively. He was an exchange student at the University of Electro-Communications of Japan, Tokyo, Japan, from October 1999 to September 2000. He was a Visiting Scholar (from January to December 2004) and a Research Associate (from November 2007 to October 2010) at Durham University, Durham, U.K. He was a Lecturer and Associated Professor with Chongqing University from 1999 to 2011 and worked in Gold Wind Science \& Technology Ltd. in 2011. In 2012, he joined Tongii University, Shanghai, China, where he is an Associate Professor with the Department of Electrical Engineering. His research interests include prognostics and health management (PHM) of power electronics, renewable energy generation, and control of electric machines.

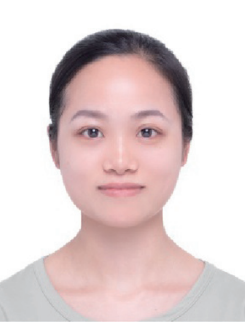

Yan Zheng received the B.S. degree in electrical engineering from Tongji University, Shanghai, China, in 2018, where She is currently working toward the M.S. degree in electrical engineering at the Department of Electrical Engineering. Her research interests include prognostics and health management (PHM) of power electronics and control of electric machines. 